International Research Journal of Management, IT \& Social Sciences
Available online at https://sloap.org/journals/index.php/irjmis/
Vol. 9 No. 1, January 2022, pages: 19-25
ISSN: 2395-7492
https://doi.org/10.21744/irjmis.v9n1.1981

\title{
Information and Communication Technologies, Their Impact on the Teaching-Learning Process
}

\author{
Richard Eduardo Sánchez Bravo ${ }^{a}$ \\ María Rodríguez Gámez ${ }^{\mathrm{b}}$
}

Article history:

Submitted: 27 September 2021

Revised: 09 October 2021

Accepted: 18 November 2021

\section{Keywords:}

cognitive processes; communication;

education;

learning process;

technology;

\begin{abstract}
Information and communication technologies allow human beings to develop their usual activities in less time, especially allowing teachers to carry out innovative educational activities. The objective of this research is to analyze the technological tools and their impact on the teaching-learning process of the "Aurelio Salazar" Educational Unit. The qualitative method was applied to study the depth levels of the teaching process, the inductive-deductive method to be able to deduce from what was studied the behavior of this methodology and its incidence in education, the bibliographic review. As an innovation of the teacher, there is the adoption of new technologies as an educational tool to achieve the realization of activities, managing to develop new knowledge and significant experiences for the student. It was obtained as a result that the PBL is one of the methodologies most used by teachers, which allows them to specify activities and projects with the help of technological tools, allowing them to effectively develop the skills of students, acquiring experiences that allow them to solve problems in your community in a responsible way, always practicing ethical and moral values.
\end{abstract}

International research journal of management, IT and social sciences (C) 2022. This is an open access article under the CC BY-NC-ND license (https://creativecommons.org/licenses/by-nc-nd/4.0/).

\section{Corresponding author:}

Richard Eduardo Sánchez Bravo,

Pontificia Universidad Católica del Ecuador, extensión Manabí, Portoviejo, Ecuador.

Email address: rsanchez9118@pucesm.edu.ec

\footnotetext{
Pontificia Universidad Católica del Ecuador, Sede Manabí, Portoviejo, Ecuador
}

${ }^{\mathrm{b}}$ Universidad Técnica de Manabí, Portoviejo, Manabi, Ecuador 


\section{Introduction}

Education is subjective, but with clear objectives, educating constitutes the sum of procedures in which a beginning led by different means is proposed to reach an end, that is, there must be resources that allow the achievement of the objectives educational, such as each Educational Unit must build its own pedagogical proposal according to the environment where it operates to achieve that desired end. In order to achieve quality education, it is necessary to always have the strategies, policies and educational resources available that allow its proper development (Vásquez, 2012). It could easily be said that education is the basis for being successful in life, however, learning is a complicated process. Currently, basic issues such as how to learn, how to acquire knowledge are discussed; In addition, there are factors that must be part of the learning process, such as reasoning, self-realization, growth, accomplishment, effort, recognition, among others. Teaching is allowing others to learn (García, et al., 2015).

The main function of the teacher in the current teaching and learning process is to guide or accompany the student in an effective and affective way, adopting Information and Communication Technologies (ICT) in their pedagogical accompaniment, managing to transfer knowledge in an interactive way, instituting new environments that break down the barriers of traditional teaching (Ruz, 2021). ICT tools have become a strategy that allows the teacher to use them in the teaching-learning process to motivate, enthuse, achieve attention and transmission of content of the different subjects that are included in the curriculum of each educational institution (Acosta et al., 2017). The main members of the educational communities where teachers and students are included as fundamental factors in this analysis, consider technological tools as effective resources to transmit knowledge, new technologies allow an expansion in learning environments, which become resources indispensable in the process of teachinglearning, noting that in the training of teachers should employ the use of these technologies asteaching resource and support within the classroom (Barragán et al., 2017).

Good use of These tools in the teaching-learning process establish a training function, not only for the student, but also indirectly impacting the family environment in a positive way, virtual spaces have become an innovative strategy in education. In the case of catastrophic events for humanity such as COVID-19, which is a pandemic that has affected globally in recent years declared by the World Health Organization (WHO) in March 2020 El Universo (2020), so humanity has had to adapt to this new way of transmitting knowledge, currently technological tools are the main protagonists in communication between the teacher, student and family (León et al., 2017). Due to the pandemic, changes are being experienced in all areas, especially in education, transitioning traditional teaching to an innovative way. This means that traditional strategies have moved into a new form through the use of new technologies, demonstrating that positive results have been obtained in these processes within the classrooms (Mora Umaña, 2018).

The educational units before applying technological strategies in their teaching-learning process must carry out a fusion study between the teaching method applied with the new digital technologies, to mitigate possible problems in the adaptation of the actors of the educational community, allowing that students consolidate their knowledge in an analytical and technological way López (2017), teaching strategies have also been used as innovative action in learning problems in schools in Manabí (Gámez et al., 2020). At this time, innovative ideas expire in very short times, not allowing to change processes that do not have positive changes, obtaining adverse results, especially in education. The application of innovative ideas in the learning environment will allow the success of the method used to achieve the proposed educational objectives (García \& Ruiz, 2020). The use of new technologies still causes some rejection by a certain group of teachers, many of them fearful of incorporating them into their work planning in the classroom because they do not know how to use them, managing to evolve and understand that this process of change that leads to the adoption of new schemes in the teaching and learning process (Rodríguez, 2006). Other authors have worked in the Marker movement, as this strategy in the construction of knowledge (Cevallos et al., 2020). The students, unlike the teachers, have assimilated ICT as a normal instrument, they have become experts in the application of these that apply it as fundamental strategies at the time of carrying out a certain academic activity, influencing the acquisition of clearly structured knowledge (Aguirre et al., 2020). To carry out the research, the objective was to analyze the incidence of the new Information and Communication Technologies in the teaching-learning process (Başar et al., 2001; Inhoff \& Radach, 1998).

\section{Materials and Methods}

For the research, the qualitative method was applied to study the depth levels of the teaching process, the inductivedeductive method to be able to deduce from what was studied the behavior of this methodology and its incidence in 
education; In addition to the bibliographic review, the desk research known as desktop research was used, which presents material published in reports and similar documents available on websites, public libraries, among others (Eyrich et al., 2008; Akyildiz et al., 2008).

\section{Results and Discussions}

The use of information technologies is a process that uses a composition of media and methods of collection, production and transmission of information, favorite resources of innovative teachers to create content that influences interactively and significantly in student learning causing an indirect and positive impact on the family environment, an experience that is common and positive (Psacharopoulos, 1994; Calderhead, 1989). For the development of the work, some methodologies developed by some authors were taken into account, as shown in Figure 1, the main methodologies applied in the 21 st century, which are used today in the Ecuadorian educational system.

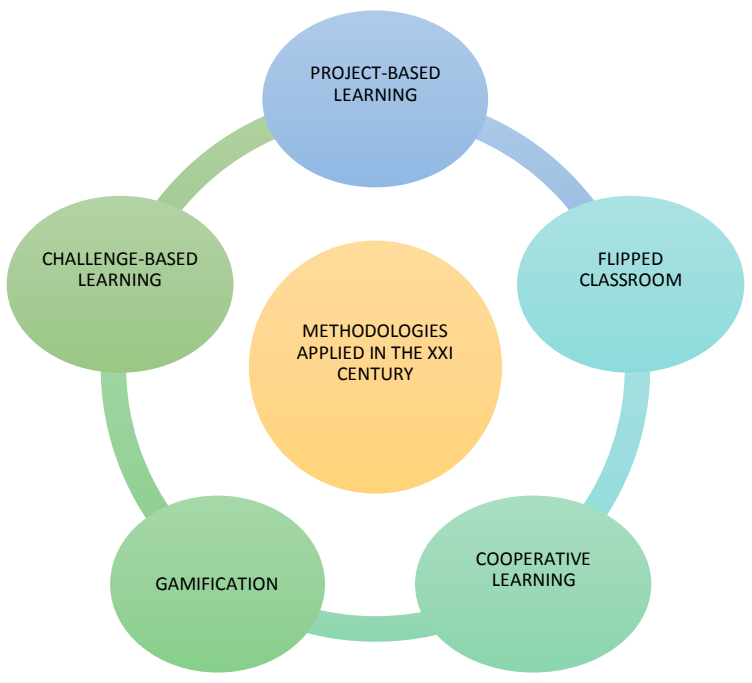

Figure 1. The main methodologies applied in the 21 st century

Teachers at different educational levels carry out activities for learning mostly in a traditional way, especially in underdeveloped countries, the most common limitations are the lack of training and the situation economic environment that happens. Since the beginning of the 21 st century, education has been changing its traditionalist and behaviorist characteristics, due to the evolution of man and technology, since the latter is part of all human activities. In 2020 all the sectors that make up a country had to use strategies in the activities they normally carry out due to the pandemic that began to affect all human beings worldwide, including the education sector, this made governments through the Ministry Education will embrace and apply new educational methodologies that adapt to the reality in which we have been going through since then, among them the Project-Based Learning (PBL) methodology was chosen, it was also applied in some research carried out in Ecuador Project-based Learning Strategy: an innovative proposal for local education system (López et al., 2020).

The ABP is a learning methodology that within its innovative process allows the student to reflect and create knowledge through experience which allows them to solve real problems within their experiential environment individually or as a team, in this method the Educating builds ideas, learns to make judgmental decisions, is self-critical and constructivist critic (Montes \& Machado, 2011). Protocol for the elaboration of an interdisciplinary project based on the PBL methodology:

Bravo, R. E. S., \& Gámez, M. R. (2022). Information and communication technologies, their impact on the teachinglearning process. International Research Journal of Management, IT and Social Sciences, 9(1), 19-25. 


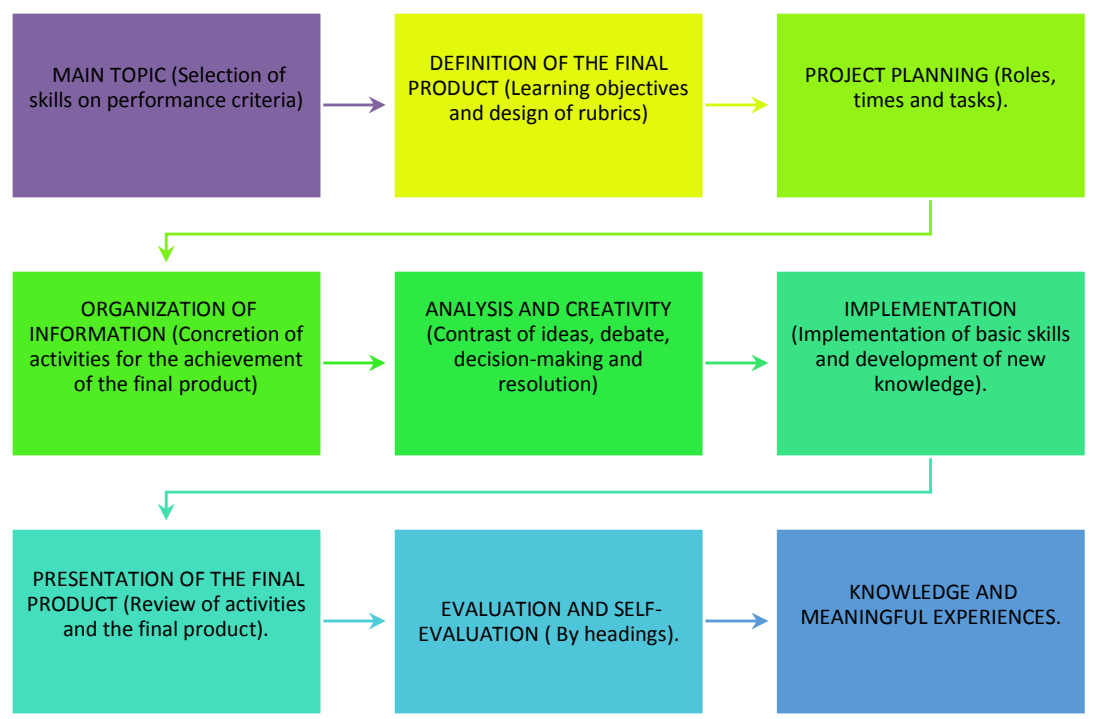

Figure 2. Protocol for the elaboration of a PBL

As noted, to carry out an interdisciplinary project with technological tools based on the PBL methodology, the following steps must be considered:

1) Main topic: Every Educational Unit is regulated according to the Organic Intercultural Education Law (LOEI) and executes its plans according to the guidelines issued by the Ministry of Education which has a National Education Curriculum, a MACRO document that contains objectives, skills, and evaluation indicators. The Annual Curricular Plan (PCA) of each Educational Institution in Ecuador is built based on the curriculum, selecting the objectives, skills and evaluation indicators to work in a specific period, that is, to specify the main topic of an interdisciplinary project, they are selected the objectives and skills with performance criteria of the subjects that make up the interdisciplinary project.

2) Definition of the final product: With the objectives and skills with selected performance criteria, the final product is determined, it must be clear and flexible, in its presentation or exposition the final product must demonstrate the skills developed by the student, the evaluation rubrics and Self-evaluation are an important part of this learning process, they should always be exposed before the execution of the project.

3) Planning of the interdisciplinary PBL project: Starting from the previous information about the project, it must be planned in a structured way as established by the educational institution, in the planning it must contain informative data of those who elaborate, execute and evaluate; the skills selected in an organized manner, resources that will be needed, methodology to be applied, activities to be carried out, evaluation indicators, recommendations, bibliography and responsibility signatures.

4) Organization of the information: With an advance call, the management team meets to create the interdisciplinary project with its respective activities, the information must be selected according to the context that the educational community develops, considering all possible scenarios, that is, these activities have to be specified as a way to achieve the pre-established final product.

5) Analysis and creativity: The organized information is analyzed as a team, granting points of view about the main idea and the concretion of activities which must lead towards the objective of the interdisciplinary project, that is, there must be the hiring of ideas, debates, decision-making and finally resolutions must be drawn up.

6) Execution: The project enters into execution when it is approved by resolution by the management team and those responsible, this can be specified in parts or in full, according to the student's context, always with the support of the teacher or professional, it is important to point out that in the course of its execution will also be its evaluation, that is, it is evaluated both in the process and in the final product.

7) Presentation of the final product and activities: Once the deadline for presentation of the final product and activities has expired, the management team and responsible personnel will proceed to collect the information and verify the skills developed by the students through the evidence. 
8) Evaluation and self-evaluation: All evaluation will be carried out through rubrics designed in stage 2, which must be designed according to the context of the project, the evaluation will be carried out by the teacher according to the evidence presented by the students and the self-evaluation will be carried out by the teacher. Student, becoming self-critical of his own actions.

Significant knowledge and experiences: The student through previous knowledge become a builder of new experiences that make him a solver of real problems that arise in his community, that is, he becomes a proactive entity for his environment. The Educational Unit "Aurelio Salazar" of the city of Chone, a survey was applied where the results shown in table 1 were obtained, the behavior of the methodologies applied by the teachers.

Table 1

Methodologies applied by teachers

\begin{tabular}{ccc}
\hline Item & Frequency (\%) & Result (\%) \\
\hline Yes & 17 & 94 \\
No & 1 & 6 \\
\hline Source: Teachers at the "Aurelio Salazar" Educational Unit
\end{tabular}

$94 \%$ of the teachers surveyed state that they apply innovative methodologies in the teaching process- learning with the help of technological tools, and $6 \%$ said they did not. As an innovation of the teacher, there is the adoption of new technologies as an educational tool to achieve the realization of activities in teaching-learning, managing to develop new knowledge and significant experiences for the student (Reed et al., 2006; Macdonald, 2003).

\section{Conclusion}

Information and communication technologies are present in every activity carried out by human beings, especially in the educational field (Nehru, 2016; Suantari et al., 2018). Teachers are aware that in the teaching-learning process the different learning methodologies must be known and applied according to the student's context. The PBL is one of the most used methodologies, it helps to specify activities and projects as a technological tool, to effectively develop skills for students, acquiring experiences to solve problems in their community in a responsible way, always practicing ethical and moral values (Selwyn, 2003; Guston \& Sarewitz, 2002).

\section{Conflict of interest statement}

The authors declared that they have no competing interests.

\section{Statement of authorship}

The authors have a responsibility for the conception and design of the study. The authors have approved the final article.

\section{Acknowledgments}

We are grateful to two anonymous reviewers for their valuable comments on the earlier version of this paper.

Bravo, R. E. S., \& Gámez, M. R. (2022). Information and communication technologies, their impact on the teachinglearning process. International Research Journal of Management, IT and Social Sciences, 9(1), 19-25. 


\section{References}

Acosta, J., Parrales, M., \& Arcos, A. (2017). Application of ICT tools in the teaching-learning process. ScienceMastery, 827-840.

Aguirre, P. A. U., Jaramillo, F. Y. V., \& Luna-Romero, Á. E. (2020). El uso de las TIC en el aprendizaje en la Universidad caso UTMACH. INNOVA Research Journal, 5(1), 31-46.

Akyildiz, I. F., Brunetti, F., \& Blázquez, C. (2008). Nanonetworks: A new communication paradigm. Computer Networks, 52(12), 2260-2279. https://doi.org/10.1016/j.comnet.2008.04.001

Barragán, E., Verdugo, V., \& Quinto, O. (2017). The use of ICTs in improvement and its impact on teaching-learning processes. ScienceMastery, 138-162.

Başar, E., Başar-Eroglu, C., Karakaş, S., \& Schürmann, M. (2001). Gamma, alpha, delta, and theta oscillations govern cognitive processes. International journal of psychophysiology, 39(2-3), 241-248. https://doi.org/10.1016/S01678760(00)00145-8

Calderhead, J. (1989). Reflective teaching and teacher education. Teaching and teacher education, 5(1), 43-51. https://doi.org/10.1016/0742-051X(89)90018-8

Cevallos, M. A. M., Cedeño, Á. M. C., \& Gámes, M. R. (2020). Maker Movement: Strategy for the Construction of Knowledge in High School Students. International Research Journal of Management, IT and Social Sciences, 7(4), $1-8$.

El Universo, P. (2020). Coronavirus Covid-19: Toque de queda en Italia, confinamiento en Grecia y más medidas ante contagios.

Eyrich, N., Padman, M. L., \& Sweetser, K. D. (2008). PR practitioners' use of social media tools and communication technology. Public relations review, 34(4), 412-414. https://doi.org/10.1016/j.pubrev.2008.09.010

Gámez, M. R., López, M. J. P., \& Pachay, L. M. V. (2020). TEACHING STRATEGIES AS INNOVATIVE ACTION IN LEARNING PROBLEMS. Journal of Social transformation and Education, 1(2), 129-139.

García, FJ, Alonso, LS, Noriega, R., Romero, J., López, F., \& Fonseca, A. (2015). Teaching and learning. CULCyT: Scientific Culture and Technology, 1-12.

García, J., \& Ruiz, M. (2020). Service-learning and digital technologies: a challenge for virtual learning spaces. IberoAmerican Journal of Distance Education, 31-42.

Guston, D. H., \& Sarewitz, D. (2002). Real-time technology assessment. Technology in society, 24(1-2), 93-109. https://doi.org/10.1016/S0160-791X(01)00047-1

Inhoff, A. W., \& Radach, R. (1998). Definition and computation of oculomotor measures in the study of cognitive processes. Eye guidance in reading and scene perception, 29-53. https://doi.org/10.1016/B978-0080433615/50003-1

León, R., López, P., Flores, H., \& Martínez, P. (2017). The incorporation of information and communication technology in the teaching-learning process in the multidisciplinary academic unit of the Huasteca area. Tlatemoani: academic research journal, 22-46.

López, L. R. (2017). Inquiry into the relationship between learning and digital technologies. Education and educators, 0123-1294.

López, M. M., Meléndez, H. V., \& Gámez, M. R. (2020). Project-based Learning Strategy: An Innovative Proposal for Local Education System. International journal of psychosocial rehabilitation, 24(1).

Macdonald, J. (2003). Assessing online collaborative learning: process and product. Computers \& education, 40(4), 377-391. https://doi.org/10.1016/S0360-1315(02)00168-9

Montes, N., \& Machado, E. (2011). Teaching strategies and teaching-learning methods in Higher Education. Medical Humanities, 1-13.

Mora Umaña, A. M. (2018). Conceptions of Language and its Relationship with Higher Cognitive Processes in Teachers I and II Cycle General Basic Education Public Schools Urban Metropolitan Area, Costa Rica. Revista Educación, 42(1), 156-175.

Nehru, R. (2016). Corporate social responsibility \& education for sustainable development. International Research Journal of Engineering, IT \& Scientific Research, 2(3), 72-81. Retrieved from https://sloap.org/journals/index.php/irjeis/article/view/490

Psacharopoulos, G. (1994). Returns to investment in education: A global update. World development, 22(9), 13251343. https://doi.org/10.1016/0305-750X(94)90007-8

Reed, M. S., Fraser, E. D., \& Dougill, A. J. (2006). An adaptive learning process for developing and applying sustainability indicators with local communities. Ecological economics, 59(4), 406-418. https://doi.org/10.1016/j.ecolecon.2005.11.008 
Rodríguez, I. (2006). Childhood and new technologies an analysis of the information society and children. Politics and Society, 139-157.

Ruz, F. C. (2021). Virtual education and emergency remote teaching in the context of technical-professional higher education: possibilities and barriers. Educational Knowledge, 128-143.

Selwyn, N. (2003). Apart from technology: understanding people's non-use of information and communication technologies in everyday life. Technology in society, 25(1), 99-116. https://doi.org/10.1016/S0160791X(02)00062-3

Suantari, N. M. D. P., Suma, K., \& Pujani, N. M. (2018). Development of three tier static electricity diagnostic test to identify student conceptions about static electricity. International Research Journal of Engineering, IT \& Scientific Research, 4(5), 7-16. https://doi.org/10.21744/irjeis.v4n5.285

Vasquez, S. M. (2012). The philosophy of education: state of the art and essential lines. -. Buenos Aires: CIAFIC Ediciones.

Bravo, R. E. S., \& Gámez, M. R. (2022). Information and communication technologies, their impact on the teachinglearning process. International Research Journal of Management, IT and Social Sciences, 9(1), 19-25. 